\title{
Real-time high-speed mobility management
}

\author{
Ahmed Abdelsalam Abuelgasim¹, Mohamed Khalafalla Hassan², Mutaz Hamed Khairiª, \\ Muhammad Nadzir Marsono ${ }^{4}$, Kamaludin Mohamad Yusof ${ }^{5}$ \\ ${ }^{1-5}$ Faculty of Electrical Engineering, Universiti Teknologi Malaysia (UTM), Skudai, Johor, Malaysia \\ ${ }^{2}$ Faculty of Telecommunication, Future University, Khartoum, Sudan
}

\begin{tabular}{|c|c|}
\hline Article Info & ABSTRACT \\
\hline Article history: & High-speed mobility system has now become a serious concern for mobile \\
\hline Received Sep 14, 2020 & $\begin{array}{l}\text { operators due to the large frameworks of a heterogeneous network made up } \\
\text { of multiple cell types and different frequency bands. Handover (HO) is }\end{array}$ \\
\hline Revised Oct 20, 2021 & conducted in a real-life scenario when the user equipment (UE) moves from \\
\hline Accepted Oct 27, 2021 & $\begin{array}{l}\text { one network coverage to another by performing proper measurement with } \\
\text { high speed. HO breakdown and call loss are observed due to a high speed; }\end{array}$ \\
\hline Keywords: & $\begin{array}{l}\text { thus, high-speed mobility system needs improvement by using the UE speed } \\
\text { as one of the key measurement monitoring criteria for the long-term }\end{array}$ \\
\hline Field measurement & evolution (LTE) network. Vendor consultation has been considered in this \\
\hline Handover & paper in addition to real drive test measurement in highways. Results have \\
\hline Heterogeneous network & timing. Results also demonstrate that $120 \mathrm{~km} / \mathrm{h}$ measurement is better than \\
\hline Mobility management & $140 \mathrm{~km} / \mathrm{h}$ as UE speed. \\
\hline
\end{tabular}

This is an open access article under the CC BY-SA license.

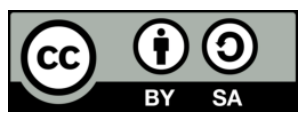

\section{Corresponding Author:}

Ahmed Abdelsalam Abuelgasim

School of Electrical Engineering, Faculty of Engineering

Universiti Teknologi Malaysia (UTM)

Skudai, 81310, Johor, Malaysia

Email: ahmedkhair22@gmail.com

\section{INTRODUCTION}

To ensure "seamless" standardization, relocation, and convergence within these heterogeneous networks, the synchronization of different cellular system technologies is essential. Hence, the use of vertical handover (VHO) approaches is required [1]. In contrast, both handover and handoff are recognized, identified once the user equipment passes to one or more cellular cells and attached to a new cell after detachment from the site of cellular origin. The handoff decision has to be made by multiple algorithms such as fuzzy logic and machine learning to address usability issues like latency and complete failure. A combination approach is being used to study cellular coverage and handover forecasts [2], [3]. The longterm evolution (LTE) technology provides stability for low user speeds from 0 to $15 \mathrm{~km} / \mathrm{h}$, and faster user speeds from 15 to $120 \mathrm{~km} / \mathrm{h}$, as per the 3 rd generation partnership project (3GPP).

Furthermore, mobility via the mobile network can still be achievable at speeds ranging from $120 \mathrm{~km} / \mathrm{h}$ to $350 \mathrm{~km} / \mathrm{h}$, but once again the effect on mobility management and quality (i.e. delay time) in the circuit switch (CS) system handover would be less than or similar to that [4]. The heterogeneous wireless networks are classified as a hybrid infrastructure of high and low power mobile cells. Some have restricted connectivity setup and others can ignore wired backhaul [5]. High frequencies are required when heterogeneous networks are introduced, as there is a correlation between frequency and cell coverage, so mmWaves are known for use in international mobile telecommunications (IMT) and the next-generation technology-5G [6]-[8]. 
This paper discusses the mobility management issues as handover delay may occur when user equipment (UE) moves with a high speed of $140 \mathrm{~km} / \mathrm{h}$ between two adjacent LTE cells vertically. The handover (HO) preparation time, including $\mathrm{HO}$ measurement, will take longer than in typical HO situations and overall HO time. Therefore, the high-speed UE may cross the HO area between the cells before the required measurement report is received by the serving cell to decide whether to proceed with the HO procedure or the call is dropped.

Anas et al. [9] the author performed an algorithm for handoff using signal strength to accelerate a decline in $\mathrm{HO}$ amount. Whenever the UE velocity is between $3-120 \mathrm{~km} / \mathrm{h}$, the algorithm has to increase the time to trigger and reduce the signal to interference and noise ratio (SINR). Bai et al. [10] studied velocity and quality of service (QoS) for evolved node B (eNB) and femtocell handover to minimize unnecessary handoff. The UE velocity is categorized into three classes $(0-15),(15-30)$, and $(>30) \mathrm{km} / \mathrm{h}$ to prevent unsuccessful calls. The algorithm neglects services that are not in real-time. Lee et al. [11] provided a HO mechanism to analyze the ping-pong handover, the latency of handover, and the failure of radio links for each handover when the UE speed is in the range of 3, 15,30,60, and $120 \mathrm{~km} / \mathrm{h}$. The UE speed has a direct negative effect on radio link failure and ping-pong; however, radio link failure remains stable when the time to trigger is $5120 \mathrm{~ms}$. Xu et al. [12] generated an algorithm that periodically (every $100 \mathrm{~ms}$ ) measures the reference signal received power (RSRP) and UE speed value. The UE speed recorded in their framework is 3, 30,60 , and $120 \mathrm{~km} / \mathrm{h}$. This algorithm's primary goal is to reduce the failed handover and ping pong in both macro and pico-cells. In [12]-[14] estimate the UE speed using the handover number counting technique during the time frame expected. The handover is more likely to fail when UE speed is high. The UE speed estimation does not work for the LTE network, which is considered a high-density network, but speed estimation works when the network is full of small cells, especially in trains. Osifeko et al. [15] studied the effect of speed $(60-120 \mathrm{~km} / \mathrm{h})$ in three different algorithms. Power, time to trigger (TTT), and handover margin (HOM) are used to avoid ping-pong via stopping the HO trigger within a certain time.

For today's wireless networks, both new and traditional systems are mixed because telecom carriers are not willing to change all of their access networks at once. In other words, a range of cellular systems offers versatile network connectivity and many solutions for end users because there are various cell sizes and various frequency bands operating on them. As a consequence, heterogeneous networks (HetNet) are composed of various cellular communication networks (i.e., 3G, LTE, and "5G" next generation). HetNet embraces the growing demand for data and the need for sufficient coverage, consistent access, and stable networks. Concerning cellular network issues, spectrum availability and capacity management are top of the list.

Given the vertical handover (VHO) of UEs through the networks, switching between various cellular technologies is a key problem. Service efficiency is affected by HO. Mobility on highways remains an unresolved and alarming problem for all mobile operators due to high-speed traffic movement that can surpass $140 \mathrm{~km} / \mathrm{h}$, which is the highway speed limit for most countries worldwide [14], [16]. To minimize the risk of call drops, UE speed must be part of handover planning, and the area of handover between adjacent cells must be measured and monitored.

\section{PROPOSED METHODOLOGY}

Conducted drive test measurements demonstrate that the cell distribution is different depending on the various cell types being introduced. The estimated coverage range is 0.4 to $3 \mathrm{~km}$. The frequency and power of operation of the cells are changed accordingly. In congested environments, low-power cells with narrow coverage areas are used to ensure continuity of service, whereas high-power cells are deployed when large coverage is required. Our early success in mobility management [16] indicates the network coverage of each LTE cell which was conducted during our field evaluation. While trying to make the cell selection/reselection during the ideal mode and the HO decision in the connected mode, RSRP is viewed as one of the main measurement parameters. As stated in [16], the signal strength variation would be between -80 to $-105 \mathrm{dBm}$ as configured in most mobile operators, whereas the classic 3GPP range is somewhere between -44 and $-140 \mathrm{dBm}$ [17], so it is clear that mobile operators are attempting to raise their rules to ensure high service quality, to avoid regulatory parties' penalties due to bad customer experience and to meet their obligations.

Table 1 illustrates the drive test setup and measurement along with LTE configuration in mobile operator network as shown in base transceiver station (BTS) site manager software. 3GPP defined LTE handover procedure in different event-based reports A1, A2, A3, A4, A5, and A6 based on timer expiry and finding the strongest cell energy with accepted quality of the signal. 3GPP has also defined triggering methods for inter radio access technology (inter-RAT) handovers in two event-based reports B1 and B2 [18]. 


\begin{tabular}{ll}
\multicolumn{2}{c}{ Table 1. Drive test and LTE cell setup } \\
\hline \multicolumn{2}{c}{ Real Mobile Operator Measurement and Setup } \\
Setup & \multicolumn{1}{c}{ Value } \\
\hline Drive test software & ACTIX \\
UE speeds & $60-140 \mathrm{~km} / \mathrm{h}$ \\
Handset type & Samsung Category 16 \\
Global cell ID & 10 \\
Physical layer cell identity & 163 \\
E-UTRAN cell identifier & 28461834 \\
Uplink (RX) frequency & $1775.0 \mathrm{MHz}$ \\
Downlink (TX) frequency & $1870.0 \mathrm{MHz}$ \\
Uplink/downlink bandwidth & $20 \mathrm{MHz}$ \\
Carrier power & $47.8 \mathrm{dBm} / 60.255 \mathrm{~W}$ \\
MIMO & Closed-Loop MIMO (4x4) \\
Virtual antenna mapping & No \\
\hline
\end{tabular}

Common network parameters are usually used during handover measurements and procedures, such as received signal strength, received signal quality, available bandwidth, UE residence time, any combination of two or more of these parameters. However, as per the common mobile operators, only received signal strength and received signal quality are used to perform the handover. Moreover, some vendors estimate the velocity of the user to achieve seamless connection. In our proposed algorithm, UE speed is added to the measurement report ahead of the handover procedure as one of the key parameters in the handover decision.

The addition of UE speed to handover measurement reports is aimed to decrease the total failure of connection during the handover and call loss. In other words, it helps to improve the overall mobile network quality and customer satisfaction. The proposed algorithm is designed for heterogeneous networks where both regular cells and small cells are implemented together.

\subsection{Proposed system architecture}

Spectrum frequency has been recently considered as a scarce resource due to the high demand for mobile and nonmobile technologies. Mobile services are currently taking the lead over other services such as broadcast and fixed services. Hence the existing and future cellular technologies are deployed in different operating frequency bands between $700 \mathrm{MHz}$ and up to $3500 \mathrm{MHz}$, which is mainly allocated for nextgeneration $(5 \mathrm{G})$ technology in most parts of the world. Due to the high demand of the spectrum, highfrequency bands (above $6 \mathrm{GHz}$ ) are also considered to be used for mobility for the first time during the international telecommunication union (ITU) world radio conference (WRC-19).

The proposed system contains two different LTE cells in terms of the operated frequency bands and output power. In the first cell, named LTE cell\#1, the frequency band is $1800 \mathrm{MHz}$ and bandwidth of $20 \mathrm{MHz}$, whereas the second cell, named LTE cell\#2, features $2600 \mathrm{MHz}$ as operating frequency band and bandwidth $20 \mathrm{MHz}$. Frequency division duplexing (FDD) is used as multiplexing mode in both LTE cells.

Furthermore, the proposed network system is similar to implemented mobile network as per the used frequency band and cell types. LTE cell radius is considered $2.7 \mathrm{~km}, 0.5 \mathrm{~km}$ for macrocell with TX power of $46 \mathrm{dBm}$ and small cell with TX power of $20 \mathrm{dBm}$, respectively, based on the real LTE deployment in mobile operators. The proposed system uses the UE speed and the RSRP of the LTE cell to consider the $\mathrm{HO}$ procedure, and the frequency band has to be defined in the configuration of LTE cells as it is vertical HO. Once the UE exceeds the defined speed threshold, the system will compare the current value of the RSRP with the defined RSRP threshold which is configured based on the average of the drive test measurements and the real configuration of the mobile operator. The handover is triggered from the serving cell to the target cell when the above mentioned conditions are met.

\subsection{Proposed simulation environment}

The proposed handover algorithm uses the MATLAB tool to simulate the handover process when UE moves at a high speed up to $140 \mathrm{~km} / \mathrm{h}$. Field measurements are performed ahead of simulation in order to compare both real measurements and simulated measurements in order to improve the overall handover. Also, the $\mathrm{HO}$ area between two adjacent cells has to be evaluated to minimize the total number of handovers and handover failures.

Frequency doppler is used in advance to measure UE speed according to 3GPP [19] as shown in (1), where $f s(t)$ are the Doppler shift, and $f d$ is the maximum Doppler frequency, which is defined to be either 5 , 70 or $300 \mathrm{~Hz}$ and the cosine of angle $\theta(t)$ is given in (2).

$$
f s(t)=f d \cos \theta(t)
$$




$$
\cos \theta(t)=\frac{\frac{D s}{2}-v t}{\sqrt{D \min ^{2}+\left(\frac{D s}{2}-v t\right)^{2}}}
$$

As stated in [20], the (3) can also be used to calculate the maximum Doppler, where $f d$ is the maximum Doppler frequency, $f c$ is the carrier frequency, $v$ is the velocity of UE, and $c$ is the speed of light.

$$
f d=v \frac{f c}{c}
$$

There is a direct relationship between the RSRP, received signal strength indicator (RSSI), resource blocks, and cell bandwidth in LTE event A3 since the UE performs measurement for both serving and target cell ahead of handover decision. Table 2 shows the number of resource blocks against LTE-defined bandwidth [21]. Since RSRP is considered as a key parameter during the HO process, the (4) shows how the RSRPP is calculated [22], where $P t x$ is transition power, $P l$ is path loss, and $L s$ is additional shadow fading. The (5) and (6) described the calculation of path loss of macrocell and femtocell, respectively, according to 3GPP [23]-[25], where $d$ is the distance between user and base station in meters and $f c$ is carrier frequency in $\mathrm{MHz}$.

Table 2. Channel bandwidth against resource blocks

\begin{tabular}{cc}
\hline Bandwidth $(\mathrm{MHz})$ & Resource blocks \\
\hline 1.4 & 6 \\
3 & 15 \\
5 & 25 \\
10 & 50 \\
15 & 75 \\
20 & 100 \\
\hline
\end{tabular}

$$
\begin{aligned}
& R S R P=P t x-P l-L s h \\
& P l(\text { Macro })=128.1+37.6 \times \log 10(d)+21 \times \log 10\left(\frac{f c}{2}\right) \\
& P l(\text { Femto })=127+30 \times \log (d)
\end{aligned}
$$

\section{EXPERIMENTAL RESULTS}

\subsection{Drive test measurement}

The optimized RSRP in network settings for telecom carriers is sufficient to keep the quality of service at a high level, even for normal low-speed users. Mobile operators face a significant threat in reducing call declines in real-time networks and delays in non-real-time networks when the UE limit is over $120 \mathrm{~km} / \mathrm{h}$. Frequent transfers occur several times through field measurement and increases as the UE speed increases, so the implementation of high-power cells will aim to minimize the risk of call decrease, but highpower cells do have drawbacks over small cells, as they cannot be used for density areas congested with humans. In addition, the inter-frequency handover was observed once the velocity is $140 \mathrm{~km} / \mathrm{h}$ during the field tests. Depending on the maximum RSRP measured, the maximum power is $-25 \mathrm{dBm}$, and if the resource blocks are 72 and the minimum bandwidth is $1.4 \mathrm{MHz}$, the maximum RSRP recorded is $10 . \log 10(72)$, which is $-44 \mathrm{dBm}$. The impact of UE speed was obvious during the conducted drive test measurement, particularly when the speed is $140 \mathrm{~km} / \mathrm{h}$, as shown in Figure 1, where the handover failure clearly happens during the handover area in the red circle.

The variation of measured RSRP during the field performed tests was recorded to be $-65 \mathrm{dBm}$ as the maximum detected value with the quality range of SINR between $-11 \mathrm{~dB}$ and $-105 \mathrm{dBm}$ when the UE is moving with a velocity of $140 \mathrm{~km} / \mathrm{h}$. Figure 2 illustrates the measured RSRP when the UE speed is $140 \mathrm{~km} / \mathrm{h}$. Moreover, a connection failure has been occurred during the mobility between two adjacent cells due to the high speed of the user, as shown by the red circle in the figure.

The conducted field measurements show better RSRP variations when UE speed is $120 \mathrm{~km} / \mathrm{h}$ through the same zone between two cellular cells in the same direction when the UE was moving with a velocity of $140 \mathrm{~km} / \mathrm{h}$. LTE signal has been impacted several times during the drive test measurement; however, no handover failure is registered. Figure 3 shows the RSRP when the UE speed is $120 \mathrm{~km} / \mathrm{h}$. 


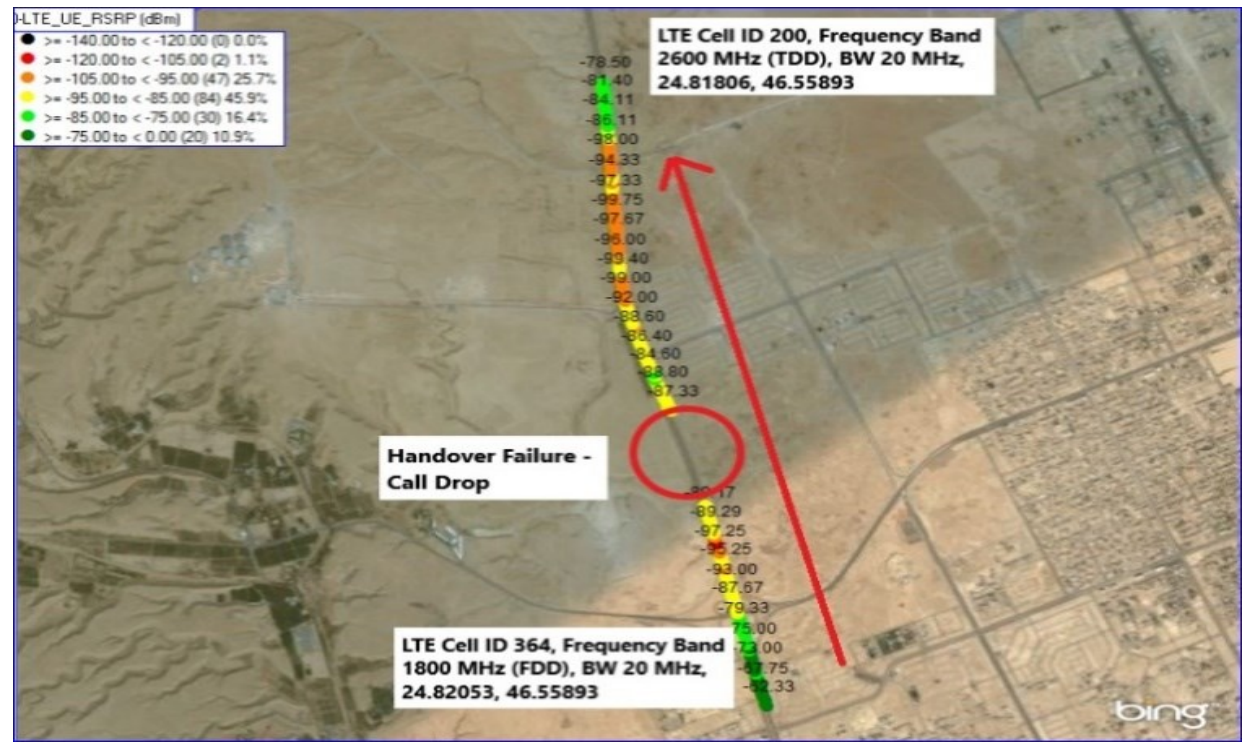

Figure 1. RSRP measurements when user equipment (UE) speed is $140 \mathrm{~km} / \mathrm{h}$ (adapted from [16])

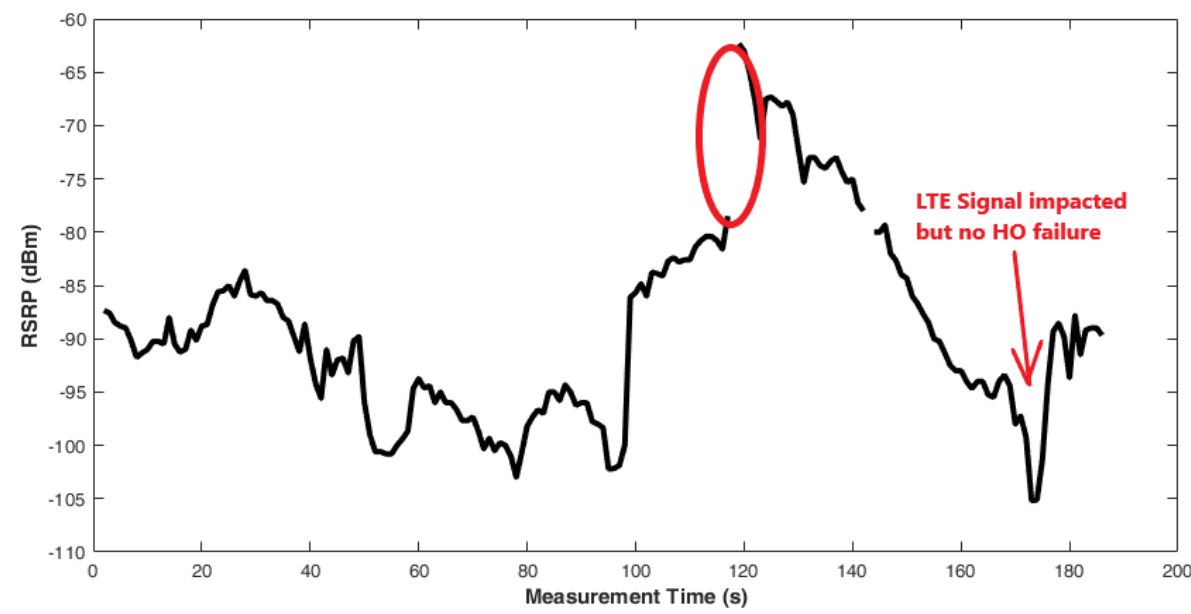

Figure 2. RSRP variations when UE speed is $140 \mathrm{~km} / \mathrm{h}$

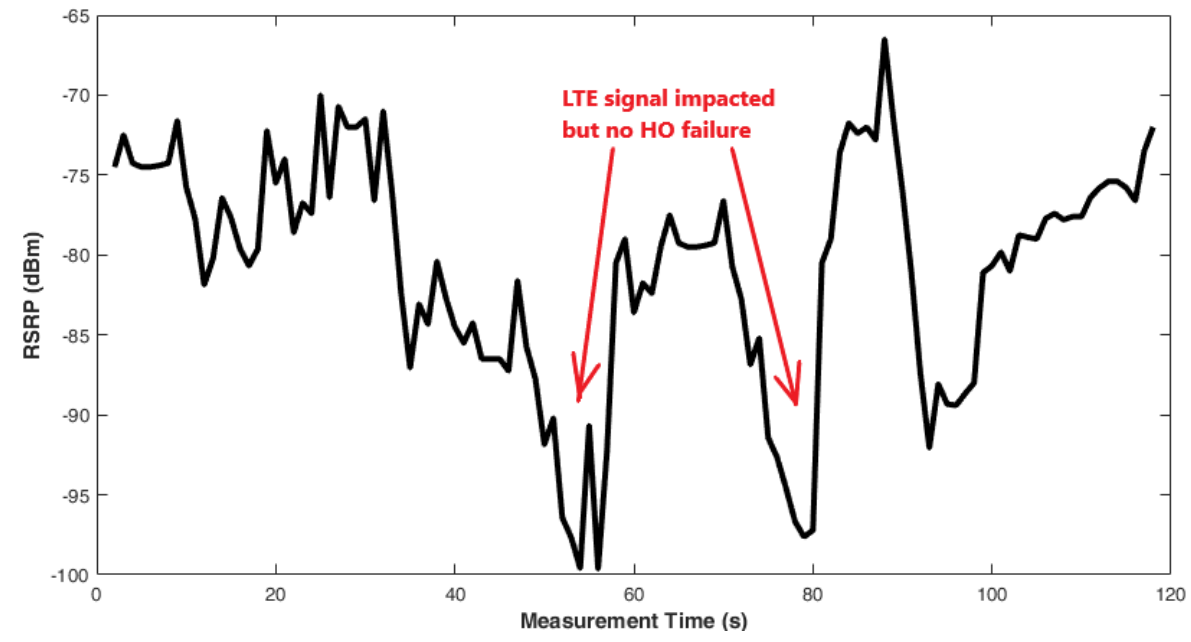

Figure 3. RSRP variations when UE speed is $120 \mathrm{~km} / \mathrm{h}$ 


\subsection{Simulation results}

The addition of UE speed in the handover preparation stage helped to improve the overall mobility management performance and maintain the network resource. Pathloss of LTE cells is included in the proposed methodology to get the received signal strength of LTE cell, either macrocell or small cell. Figure 4 shows the variation of path loss for both the standard macro cell and small cell (femtocell) according to simulated results based on (5) and (6).

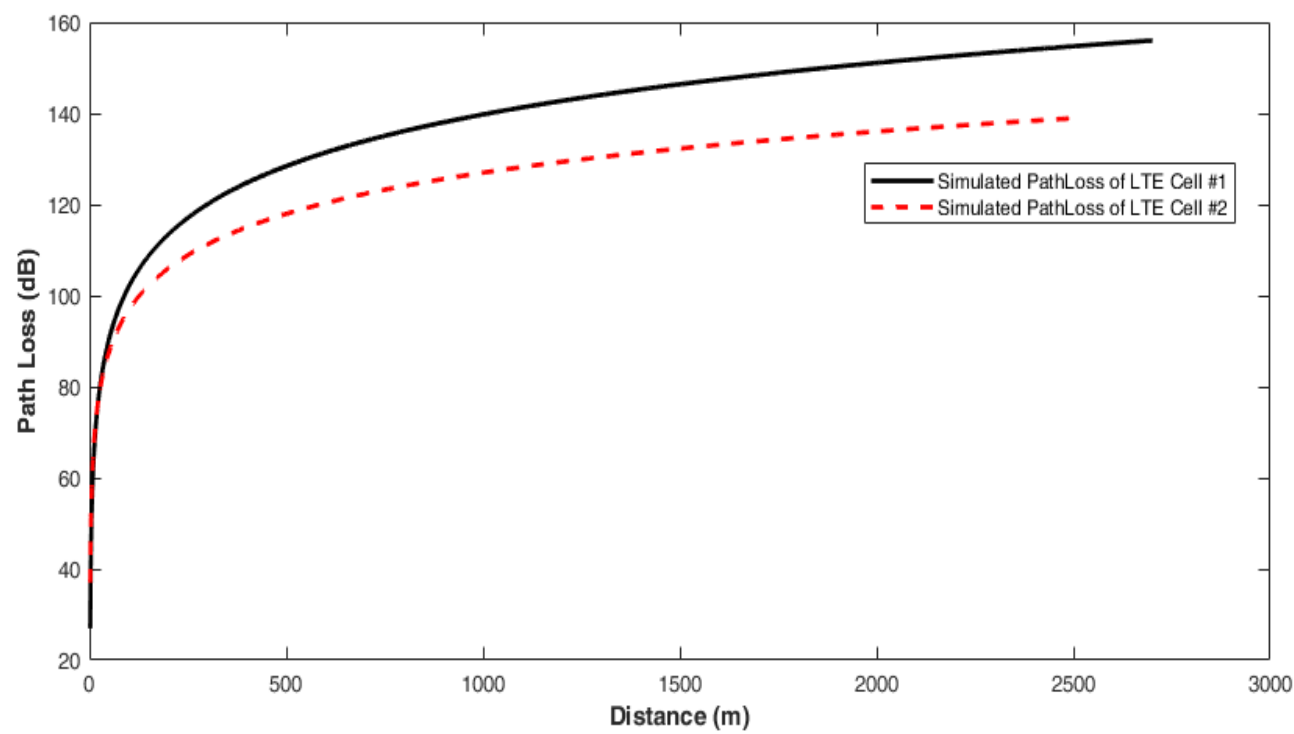

Figure 4. Path loss variations in Macrocell and Femtocell

The simulation results show that the RSRP varies by $-60 \mathrm{dBm}$ to $-132 \mathrm{dBm}$ for both LTE cells when UE speed is between $120-140 \mathrm{~km} / \mathrm{h}$; however, the mobility management performance recorded better results when the UE speed is $120 \mathrm{~km} / \mathrm{h}$. Figure 5 and Figure 6 illustrates the RSRP variation for cell ID 9, which operates with $20 \mathrm{dBm}$ as transmit power, and the best-recorded RSRP is around -79 and $-53 \mathrm{dBm}$. In comparison, the worse value is found around -100 and $-87 \mathrm{dBm}$ for drive test (DT) and simulation, respectively.

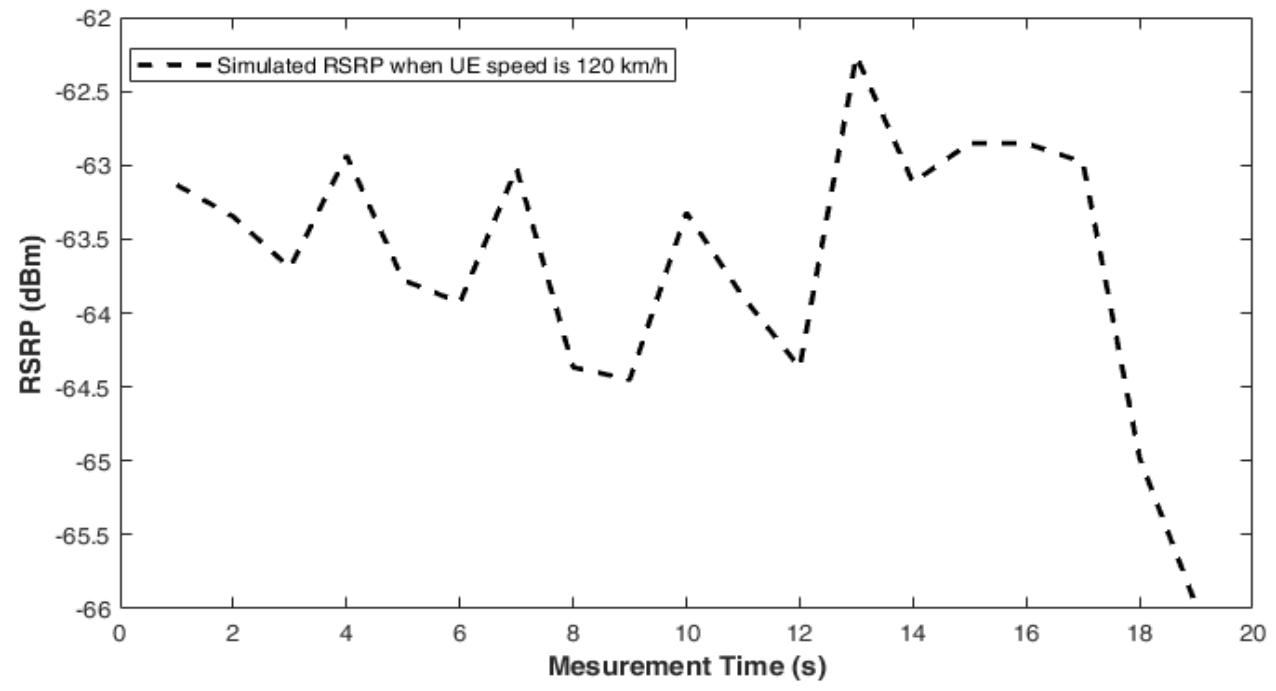

Figure 5. Simulated RSRP when UE speed is $120 \mathrm{~km} / \mathrm{h}$ 


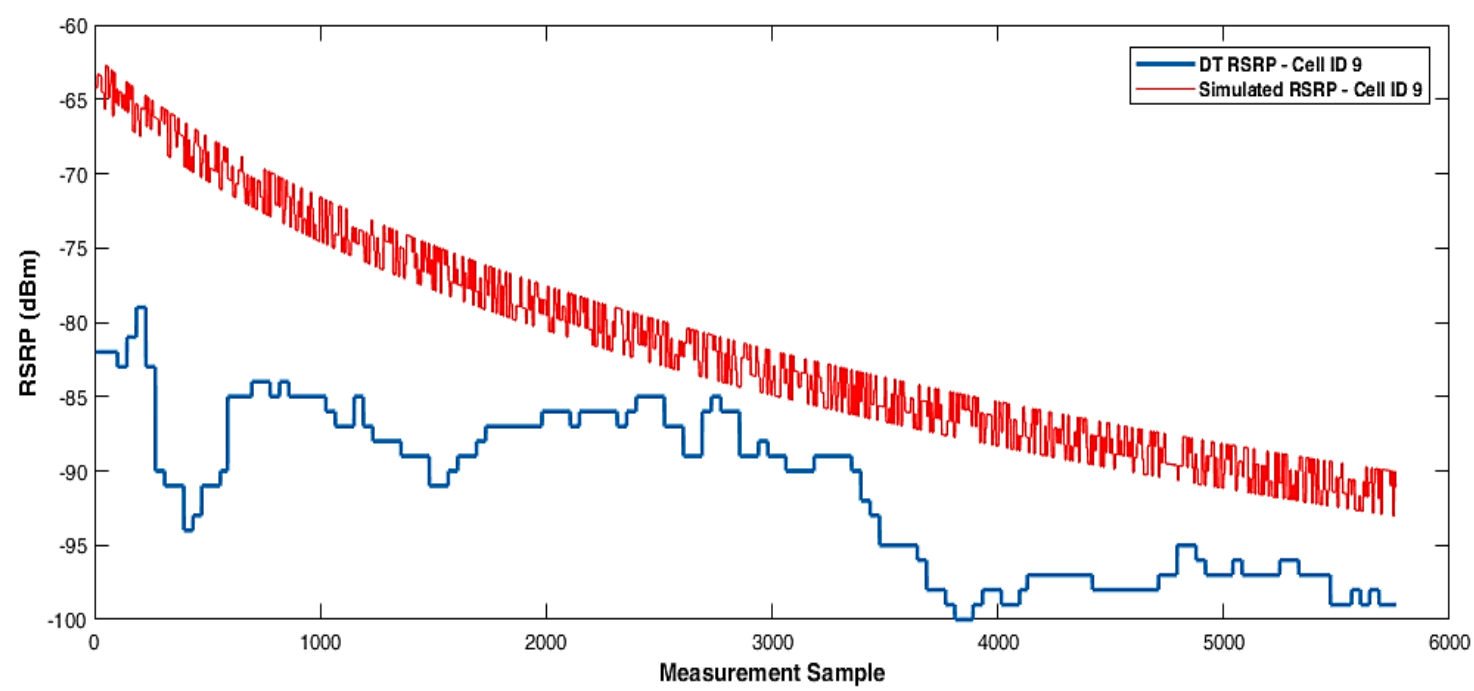

Figure 6. Simulated RSRP vs. DT RSRP for cell ID 9 and UE speed is $140 \mathrm{~km} / \mathrm{h}$

\section{CONCLUSION}

Mobility management has become annoying to mobile operators since it is directly affecting the quality of service provided to subscribers and corporates. Overall mobility management performance is evaluated for real mobile operators in the middle east by conducting a driving test for high-speed users to see how UE speed affects the overall network quality. The measured UE speed has been categorized into mid and high speed, which is $80 \mathrm{~km} / \mathrm{h}$ and $120-140 \mathrm{~km} / \mathrm{h}$, respectively. Then UE speed is considered as one of the primary handover parameters in the proposed algorithm, and any user above the high-speed limit will be ignored in the handover procedure due to illegal use of speed. Handover failure and overall handover timing are directly affected by UE speed.

\section{REFERENCES}

[1] G. Yang, X. Wang, and X. Chen, "Handover control for LTE femtocell networks," 2011 International Conference on Electronics, Communications and Control (ICECC), 2011, pp. 2670-2673, doi: 10.1109/ICECC.2011.6067552.

[2] N. C. Eli-chukwu, J. M. Aloh, and C. O. Ezeagwu, "A Systematic Review of Artificial Intelligence Applications in Cellular Networks," vol. 9, no. 4, pp. 4504-4510, 2019, doi: 10.48084/etasr.2788.

[3] M. K. Hassan, A. Babiker, M. B. M. Amien, and M. Hamad, "SLA Management For Virtual Machine Live Migration Using Machine Learning with Modified Kernel and Statistical Approach," Engineering, Technology \& Applied Science Research, vol. 8, no. 1, pp. 2459-2463, 2018, doi: 10.48084/etasr.1692.

[4] 3GPP/ETSI, (TR 25.913Mike) Universal Mobile Telecommunications System (UMTS); LTE; Requirements for Evolved UTRA (E-UTRA) and Evolved UTRAN (E-UTRAN), 3GPP TR 25.913 version 9.0.0 Release 9, ETSI, 2010.

[5] M. Zekri, B. Jouaber, and D. Zeghlache, "A review on mobility management and vertical handover solutions over heterogeneous wireless networks," Computer Communications, vol. 35, no. 17, pp. 2055-2068, 2012, doi: 10.1016/j.comcom.2012.07.011.

[6] GSMA, 5G Spectrum GSMA Public Policy Position, 2020. [Online]. Available: https://www.gsma.com/latinamerica/resources/5g-spectrum-gsma-public-policy-position-2/

[7] A. H. Nalband, M. Sarvagya, and M. R. Ahmed, "Power saving and optimal hybrid precoding in millimeter wave massive MIMO systems for 5G," TELKOMNIKA Telecommunication, Computing, Electronics and Control, vol. 18, no. 6, pp. 2842-2851, 2020, doi: 10.12928/telkomnika.v18i6.15952.

[8] R. I. Boby, K. Abdullah, A. Z. Jusoh, N. Parveen, and A. L. Asnawi, "A wireless precoding technique for millimetre-wave MIMO system based on SIC-MMSE," TELKOMNIKA Telecommunication, Computing, Electronics and Control, vol. 17, no. 6, pp. 2782-2789, 2020, doi: 10.12928/telkomnika.v17i6.12802.

[9] M. Anas, F. D. Calabrese, P. E. Mogensen, C. Rosa, and K. I. Pedersen, "Performance Evaluation of Received Signal Strength Based Hard Handover for UTRAN LTE," 2007 IEEE 65th Vehicular Technology Conference VTC2007-Spring, 2007, pp. 1046-1050, doi: 10.1109/VETECS.2007.223.

[10] T. Bai, Y. Wang, Y. Liu, and L. Zhang, "A policy-based handover mechanism between femtocell and macrocell for LTE based networks," 2011 IEEE 13th International Conference on Communication Technology, 2011, pp. 916-920, doi: 10.1109/ICCT.2011.6158012. 
[11] Y. Lee, B. Shin, J. Lim, and D. Hong, "Effects of time-to-trigger parameter on handover performance in SONbased LTE systems," 2010 16th Asia-Pacific Conference on Communications (APCC), 2010, pp. 492-496, doi: 10.1109/APCC.2010.5680001.

[12] G. X. Xu, Q. Wu, M. Daneshmand, Y. Liu, and M. M. Wang, "A Data Privacy Protective Mechanism for Wireless Body Area Networks," Wirel. Commun. Mob. Comput., vol. 16, no. 3, pp. 1746-1758, 2015, doi: $10.1002 / \mathrm{wcm} .2649$.

[13] A. Merwaday and I. Guvenc, "Handover Count Based UE Velocity Estimation in Hyper-Dense Heterogeneous Wireless Networks,” 2015 IEEE Globecom Workshops (GC Wkshps), 2015, pp. 1-6, doi: 10.1109/GLOCOMW.2015.7414125.

[14] S. Rahmatia, D. Martin, M. Ismail, O. Nur Samijayani, D. Astharini, and R. Safitri, "Automatic Cell Planning of LTE FDD $1800 \mathrm{MHz}$ Network in Klaten, Central Java," 2020 International Conference on Electrical, Communication, and Computer Engineering (ICECCE), 2020, pp. 1-6, doi: 10.1109/ICECCE49384.2020.9179483.

[15] M. O. Osifeko, A. A. Okubanjo, O. R. Abolade, O. K. Oyetola, A. O. Oyedeji, and O. I. Sanusi, "Evaluating the effect of mobility speed on the performance of three handover algorithms in long term evolution networks," $J$. Appl. Sci. Environ. Manag., vol. 22, no. 4, pp. 503-506, 2018, doi: 10.4314/jasem.v22i4.11.

[16] B. Katz, J. Ma, H. Rigdon, K. Sykes, Z. Huang, and K. Raboy, "Synthesis of Variable Speed Limit Signs," U.S. Department of Transportation, Federal Highway Administration, 2017.

[17] A. Abdelsalam and M. K. Abuelgasim, "High Speed Mobility Management Performance in a Real LTE Scenario," Eng. Technol. Appl. Sci. Res., vol. 10, no. 1, pp. 5175-5179, 2020, doi: 10.48084/etasr.3245.

[18] ETSI TS 136331 V13.0.0 (2016-01), LTE; Evolved Universal Terrestrial Radio Access (E-UTRA); Radio Resource Control (RRC); Protocol specification, (3GPP TS 36.3.331 version 13.0.0 Release 13), 2016.

[19] C. Johnson, LTE in Bullets 2nd Edition, Carolina Selatan, USA: CreateSpace, 2021.

[20] ETSI TS 136141 V13.6.0 (2017-01), "LTE; Evolved Universal Terrestrial Radio Access (E-ULTRA); Base Station (BS) conformance Testing, 3GPP TS 36.141 version 13.6.0 Release 13, 2017.

[21] O. Altrad, S. Muhaidat, and P. D. Yoo, "Doppler frequency estimation-based handover algorithm for long-term evolution networks," IET Networks, vol. 3, no. 2, pp. 88-96, 2014, doi: 10.1049/iet-net.2012.0224.

[22] H. M. T. Al-Hilfi, "Analysis of LTE physical channels overhead," TELKOMNIKA Telecommunication, Computing, Electronics and Control, vol. 18, no. 5, pp. 2800-2806, 2020, doi: 10.12928/telkomnika.v18i5.16701.

[23] K. Ghanem, H. Al-Radwan, and A. Ahmad, "A Timer based on Overlapping Area for Avoiding Ping-Pong Handover in LTE Networks," International Journal of Engineering Research \& Technology, vol. 3, no. 16, 2015, doi: 10.21928/juhd.v1n3y2015.pp369-375.

[24] G. Chopra, S. Jain, and R. K. Jha, "Possible Security Attack Modeling in Ultradense Networks Using High-Speed Handover Management," in IEEE Transactions on Vehicular Technology, vol. 67, no. 3, pp. 2178-2192, March 2018, doi: 10.1109/TVT.2017.2765004.

[25] R. Ahmad, E. A. Sundararajan, N. E. Othman, and M. Ismail, "An efficient handover decision in heterogeneous LTE-A networks under the assistance of users' profile," Telecommunication Systems, vol. 68, pp. 27-45, 2018, doi: $10.1007 / \mathrm{s} 11235-017-0374-4$ 